\title{
The effect of Ebola virus disease on maternal health service utilisation and perinatal outcomes in West Africa: a systematic review
}

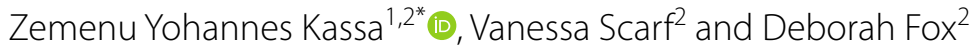

\begin{abstract}
Background: Ebola outbreaks pose a major threat to global public health, especially in Sub-Saharan Africa. These outbreaks disrupt the already fragile maternal health services in West Africa. The aims of this study is to assess the effect of Ebola virus disease (EVD) on maternal health service utilisation and perinatal outcomes.

Methods: This systematic review was conducted in West Africa, and the databases used were Medline, PubMed, CINAHL, Scopus, EMBASE and African journals online. Studies that reported the effect of the Ebola outbreak on maternal health services in West Africa were eligible for this systematic review. The search was limited to articles written in the English language only and published between 2013 and 2020. Three authors independently appraised the articles, and the data were extracted using a standardised data extraction format. The findings were synthesised using a narrative summary, tables, and figures.
\end{abstract}

Results: Twelve studies met the inclusion criteria and were used for this systematic review synthesis. The results showed that antenatal care significantly decreased during Ebola virus disease and strove to recover post-Ebola virus disease. Women were less likely to have institutional childbirth during Ebola virus disease and struggled to recover post-Ebola virus disease. In addition, this review revealed a substantially higher rate of maternal mortality post EVD than those observed before or during the outbreak.

Conclusion: Based on our findings, antenatal care, institutional childbirth, and postnatal care are attempting to recover post-Ebola virus disease. We recommended that responsible bodies and stakeholders need to prepare locally tailored interventions to increase the number of women attending ANC, institutional childbirth, and PNC services post-EVD and future outbreaks including COVID-19. In order to build trust, creating community networks between health care providers and trusted community leaders may increase the number of women attending antenatal care (ANC), institutional childbirth and postnatal care (PNC) post-EVD and during future outbreaks. Further studies are needed to examine health centre and hospital availability and accessibility, and capacity to deliver maternal health services post-Ebola virus disease and future outbreaks.

*Correspondence: zemenu2013@gmail.com

${ }^{1}$ Department of Midwifery, College of Medicine and Health Sciences,

Hawassa University, Hawassa, Ethiopia

Full list of author information is available at the end of the article

(c) The Author(s) 2022. Open Access This article is licensed under a Creative Commons Attribution 4.0 International License, which permits use, sharing, adaptation, distribution and reproduction in any medium or format, as long as you give appropriate credit to the original author(s) and the source, provide a link to the Creative Commons licence, and indicate if changes were made. The images or other third party material in this article are included in the article's Creative Commons licence, unless indicated otherwise in a credit line to the material. If material is not included in the article's Creative Commons licence and your intended use is not permitted by statutory regulation or exceeds the permitted use, you will need to obtain permission directly from the copyright holder. To view a copy of this licence, visit http://creativecommons.org/licenses/by/4.0/. The Creative Commons Public Domain Dedication waiver (http://creativeco mmons.org/publicdomain/zero/1.0/) applies to the data made available in this article, unless otherwise stated in a credit line to the data. 


\begin{abstract}
Plain Language Summary
Ebola virus disease (EVD) is a serious public health concern affecting the health of humans and other primates. These outbreaks disrupt the already fragile maternal health services in West Africa. There is limited data on the effect of EVD on maternal health service utilisation and perinatal outcomes in West Africa. This systematic review aims to synthesise evidence on maternal health service utilisation and perinatal outcomes before EVD, during EVD and post EVD.

This systematic review was conducted in West Africa, and the databases used were Medline, PubMed, CINAHL, Scopus, EMBASE and African journals online. Twelve studies met the inclusion criteria and were used for this systematic review synthesis. The results showed that antenatal care significantly decreased during the Ebola virus outbreak and strove to recover post-Ebola virus disease. This finding indicated that women were less likely to have an institutional birth during EVD and struggled to recover post-Ebola virus disease. Based on this finding, responsible bodies and stakeholders need to prepare locally tailored interventions to increase the number of women attending ANC, institutional childbirth, and PNC services post-EVD and future outbreaks.
\end{abstract}

Keywords: Ebola virus disease, Maternal health, West Africa

\section{Background}

Ebola virus disease (EVD) is a serious public health concern affecting the health of humans and other primates [1]. The causative agent of Ebola is an RNA virus of the family Filoviridae, genus Ebolavirus. There are five known strains of the Ebola virus: Zaire Ebola virus (EBOV), Sudan Ebola virus (SUDV), Bundibugyo Ebola virus (BDBV), Forest Ebola virus (TAFV), and Reston Ebola virus (RESTV) [2-4]. Three of the above viruses are seriously pathogenic and lethal to humans. In contrast, the Reston virus is only pathogenic to non-human primates [5], and the natural reservoir of Ebola virus disease is in fruit bats $[2,6]$.

EVD is a virulent and extremely contagious viral haemorrhagic fever (VHF) [7], and its mode of transmission from person to person is via direct contact of the skin or mucous membranes with infected bodily fluids $[1,8,9]$. It was first discovered in 1976 in Zaire [10]. The 2014 Ebola outbreak posed a major threat to global public health, especially in West Africa. The first Zaire Ebola virus case was reported in December 2013 in Guinea, and it subsequently spread to Sierra Leone and Liberia [11]. The World Health Organization (WHO) declared the Ebola outbreak a public health emergency on August 8, 2014 [12]. From 2013 to 2016, 28,616 people had contracted EVD, and 11,310 people had died due to the Ebola virus disease in West Africa [13].

Similarly, maternal and neonatal deaths increased; directly by contracting the virus and indirectly through the overwhelming need for maternal health services [14]. In the last three decades, evidence showed that maternal mortality significantly decreased in three West African countries (Guinea, Liberia, and Sierra Leone) prior to EVD [15]. However, the EVD outbreak has reversed this tremendous progress in reducing maternal mortality [16-18]. Maternal and child health experts, policymakers and governments have implemented different intervention strategies to increase maternal health service utilisation in three West African countries before EVD (Guinea, Liberia, and Sierra Leone) [19]. These strategies include, for example, preparing maternal waiting rooms $[20,21]$, providing free health services [22], training and deploying midwives at health institutions [23], and community engagement in health [24].

Despite the above, interventions, maternal and neonatal morbidity and mortality are still high in these countries. In 2013, there were an estimated 650 maternal deaths per 100,000 live births recorded in Guinea, 640 maternal deaths per 100,000 live births recorded in Liberia, and 1100 maternal deaths per 100,000 live births recorded in Sierra Leone [25]. Furthermore, an estimated 30 perinatal deaths per 1000 live births occurred in Liberia in 2013 Demographic and Health Survey (DHS), and 39 perinatal deaths per 1000 live births occurred in Sierra Leone in 2013 DHS. The pooled estimated was 36 perinatal deaths per 1000 live births in West Africa [26].

Ebola virus disease has decreased institution-based childbirth [27, 28], devastating impact on the health system and health care providers $[29,30]$ and caused thousands of maternal and neonatal deaths. Due to these factors, there has also been an increase in maternal and neonatal morbidity and mortality through direct and indirect impacts on institutional childbirth [28, 31]. In 2014, the United Nations Population Fund projected that 120,000 maternal deaths could have occurred due to disruption of the Ebola outbreak if the necessary lifesaving emergency obstetrics care had not been urgently deployed across Guinea, Sierra Leone, and Liberia [30].

The EVD outbreak disturbed the already weak maternal health services [32,33] due to ignorance, lack of supplies, or the shifting of health staff, equipment from the maternal service to EVD management $[34,35]$ and shut down public health facilities [36]. Additionally, medical health care providers' deaths, the absence of health 
care providers, the fear of being exposed to body fluids at health facilities $[37,38]$, and women's belief that health facilities could be a source of Ebola transmission [39, 40], along with a negative attitude about the staff [41], has disrupted maternal health service utilisation.

While some systematic reviews have focused on determining the impact of the Ebola virus disease outbreak on maternal health service utilisation [28], these have not shown the effect of the Ebola virus disease outbreak on perinatal outcomes. A previous systematic review focused on barriers to maternal health services during the Ebola virus disease outbreak [42]. Therefore, this systematic review aims to synthesise evidence of the effect of the Ebola virus disease outbreak on maternal health service utilisation and perinatal outcomes.

\section{Methods}

\section{Bibliographic data bases search strategies}

This systematic review was limited to peer-reviewed, published studies. The search strategy included the following databases: Medline, PubMed, CINAHL, Scopus, EMBASE and African journals online. Using special index search terms (medical subject headings (MeSH)) "Maternal health service" OR "reproductive health service" OR "maternal and new-born health service" OR "antenatal care" OR "postnatal care" OR "maternal primary care" OR "obstetrics care" OR "maternal-child health services" AND "Ebola*" OR "haemorrhagic fever" AND "utilisation" OR "access" OR "uptake" OR "availability" AND "West Africa". In addition, additional articles were retrieved by using cross-referencing of references, titles, and abstracts. We registered our protocol with Prospero international register of systematic reviews (http://www.crd.york.ac.uk/PROSPERO/) in September 2020 (CRD42020202548). The Preferred Reporting Items for Systematic Reviews and Meta-Analysis (PRISMA) checklist [43] was utilised to present the findings on the impact of Ebola on obstetric care in West Africa (Fig. 1).

\section{Inclusion and exclusion criteria}

Studies that reported the impact of the Ebola outbreak on maternal health services in West Africa were eligible for this systematic review. The search was limited to English language articles only, and articles published between 2013 and 2020 were included. Quantitative studies of cross-sectional, ecological, retrospective cohort and prospective cohort study designs in West Africa were included, irrespective of whether the study was implemented in a health facility and/or in the community.

Review articles, notes, editorial letters, commentaries, studies where the participants were not human, case reports, conference abstracts and proceedings, articles with incomplete information, articles with methodological problems or with full text not available and studies that reported the impact of Ebola on the health system without reporting its impact on maternal health services were excluded. When multiple publications of the same data exist, we used the most inclusive, comprehensive, and recent articles.

\section{Data quality appraisal}

Three authors (ZYK, VS and DF) independently extracted data using a standardised data extraction format. The data extraction was performed using the Joanna Brigg's Institute (JBI) critical appraisal checklist for simple prevalence, which contains nine checklist items. The tool contains nine criteria to assess the quality of the studies, such as the appropriateness of the sampling frame and sampling method; adequacy of the sample size; complete descriptions of the study setting and participants, data analysis, statistical analysis, and response rate; the validity of the methods used to identify the condition; and the reliability of measurements between study participants [44]. Based on the above criteria, three authors (ZYK, VS and DF) independently assessed the quality of the articles. Any disagreement was resolved through discussion and consensus among the three authors. The quality of the study was evaluated, and studies that scored $\geq 5$ out of 9 were included in this systematic review. Finally, the selected articles that met the inclusion criteria were retained for the narrative synthesis.

\section{Data synthesis}

We employed a narrative synthesis approach to present the findings of this systematic review [45]. We evaluated the impact of EVD on different maternal health services, including antenatal care [1-4], facility-based childbirth, caesarean section, and postnatal care, which are all part of the continuum of care [46]. Finally, summary tables were produced from the crude data demonstrating the impact of the Ebola outbreak on maternal health services (Table 1).

\section{Operational Definition}

Maternal health services are those providing antenatal care, institutional childbirth, and postnatal care.

Antenatal care is the care received by women during pregnancy from skilled health care providers at least once at a health facility.

Institutional childbirth is childbirth attended by skilled health care providers at health facilities.

Postnatal care is received by women from skilled health care providers at health facilities from 48 hours to 6 weeks after childbirth.

Stillbirth is the death of a baby before or during birth after 28 weeks of gestation. 

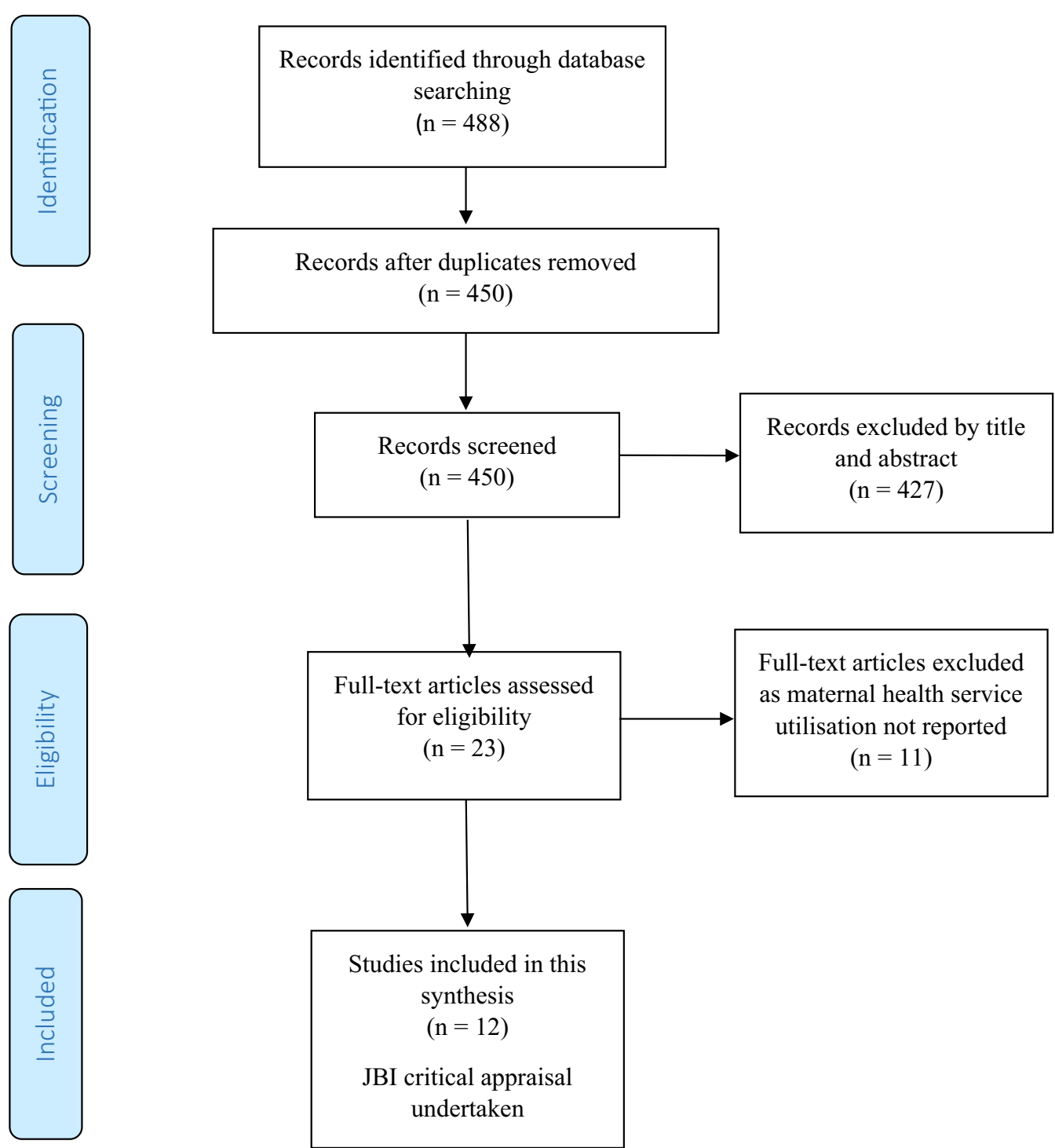

Fig. 1 PRISMA (Flow chart of study selection for a systematic review of the effect of Ebola virus disease on maternal and neonatal health services utilisation in West Africa)

Neonatal death is the death of a baby within the first 28 days of life.

Perinatal mortality is stillbirth plus early (less than seven days) neonatal death.

\section{Results}

Our search strategy retrieved 488 articles from the selected databases that were eligible for first-round screening of titles and abstracts. Thirty-eight articles were excluded due to duplication, 427 articles were excluded based on their titles and abstracts, and the remaining 23 articles were appraised with a full-text screening. Eleven articles were excluded after a full-text review due to unreported maternal health service utilisation. Finally, 12 studies [16-18, 35, 39, 47-53] were included for this systematic review that met the critical appraisal checklists, irrespective of their study design (Fig. 1).

\section{Characteristics of the included studies}

Two-thirds (8 studies) of the included articles were crosssectional study designs, and the remaining articles were case series, ecological, retrospective cohort and prospective cohort studies. More than 40\% (5 studies) of the included articles were published in 2017, one-fourth of the included articles were published in 2016, and 


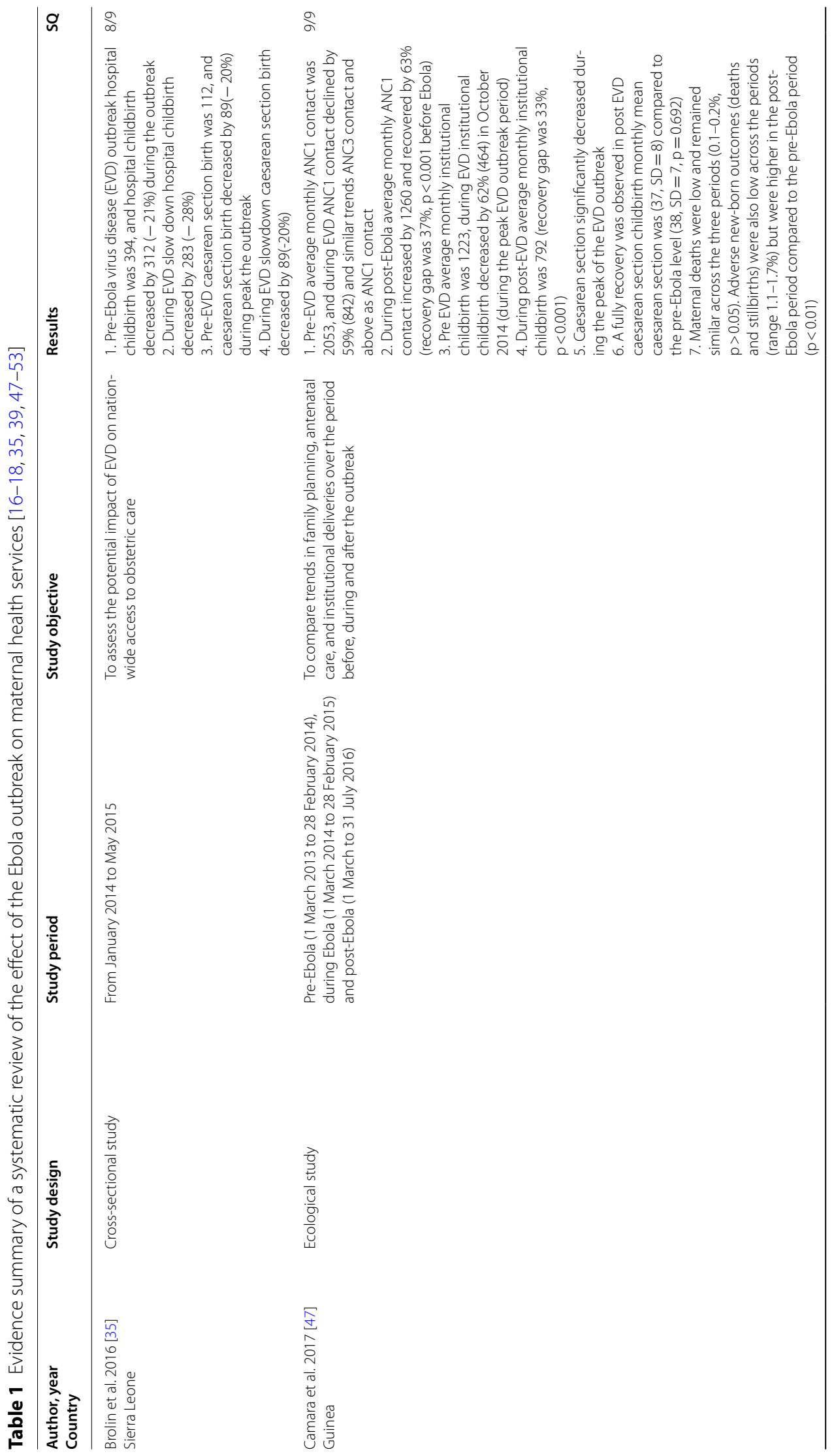




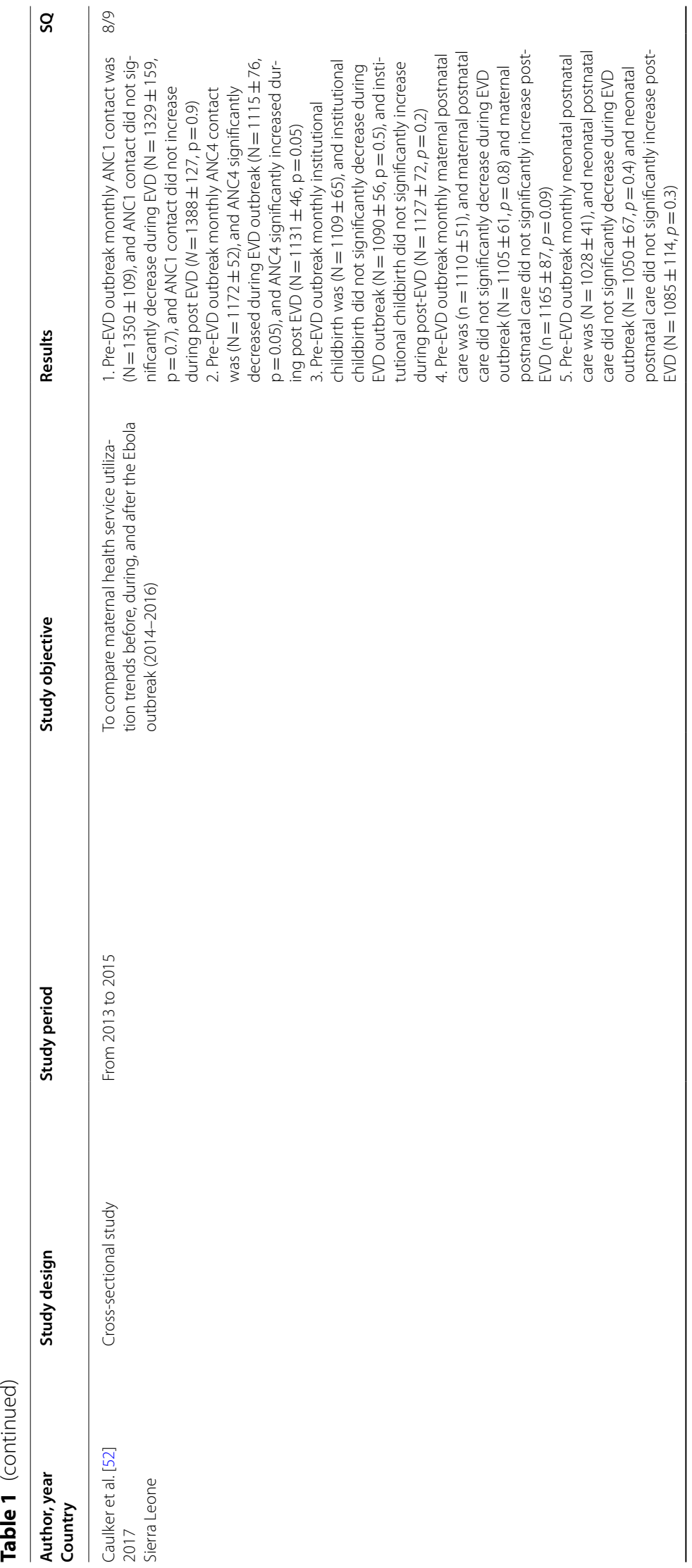




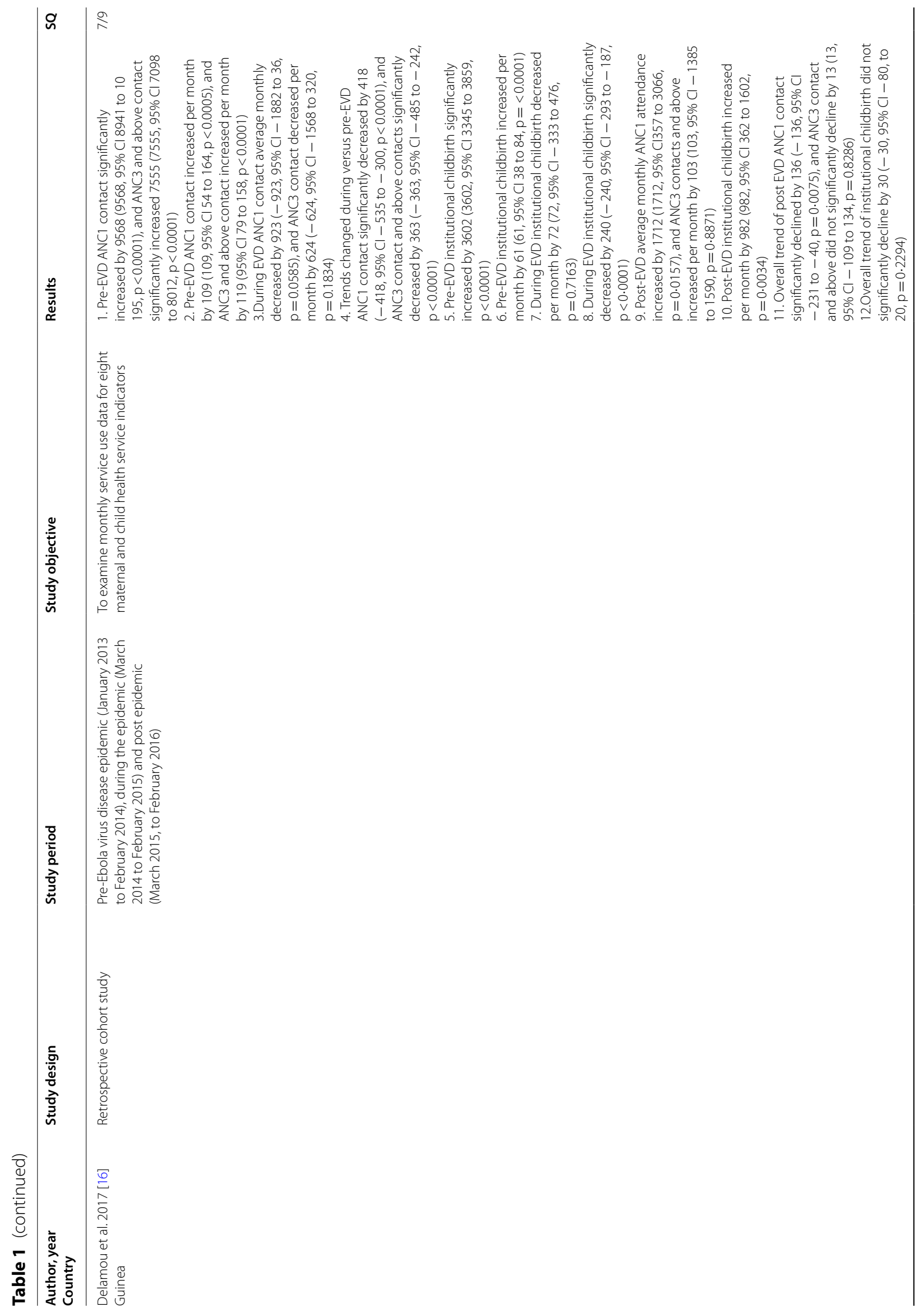




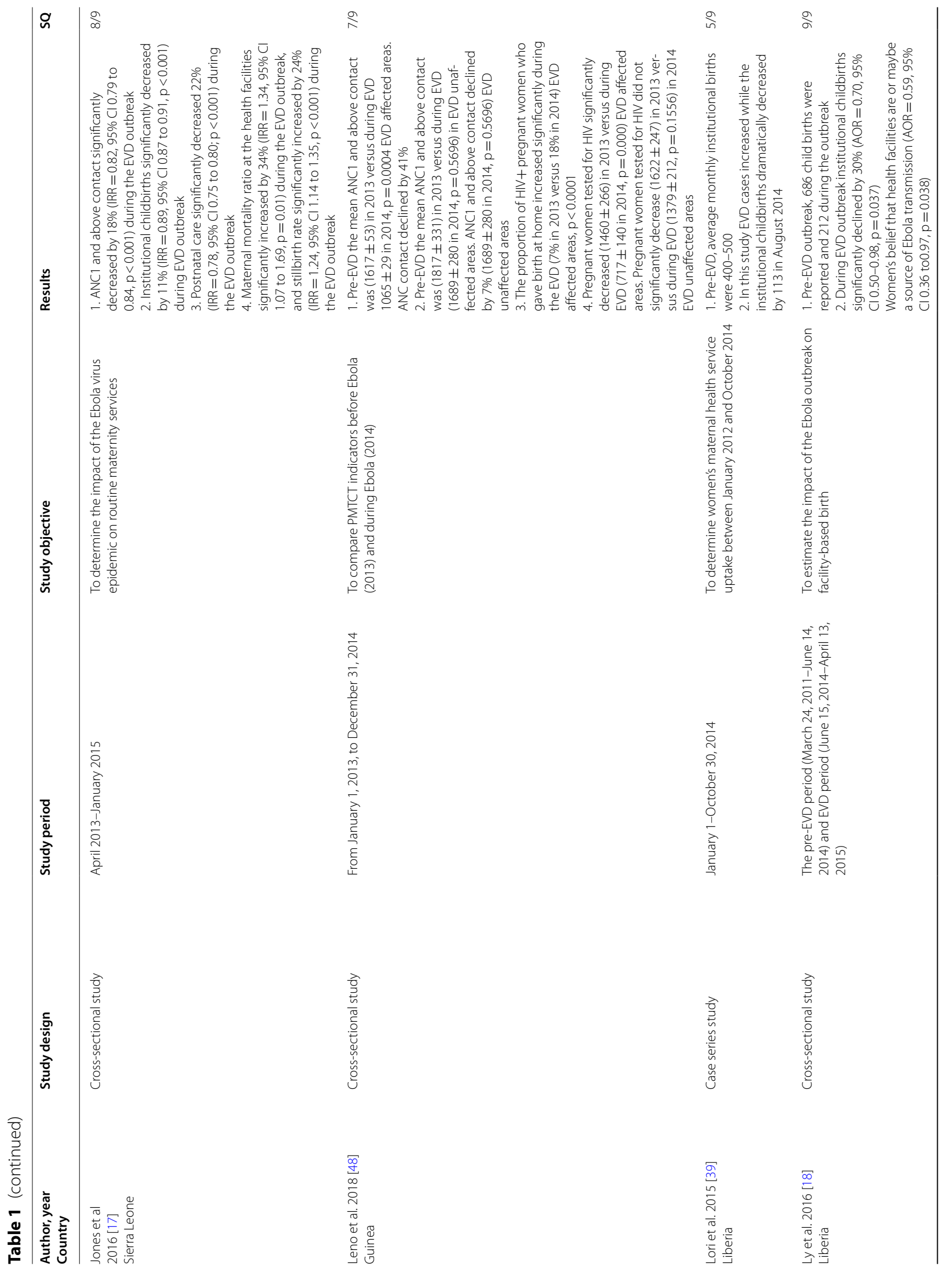




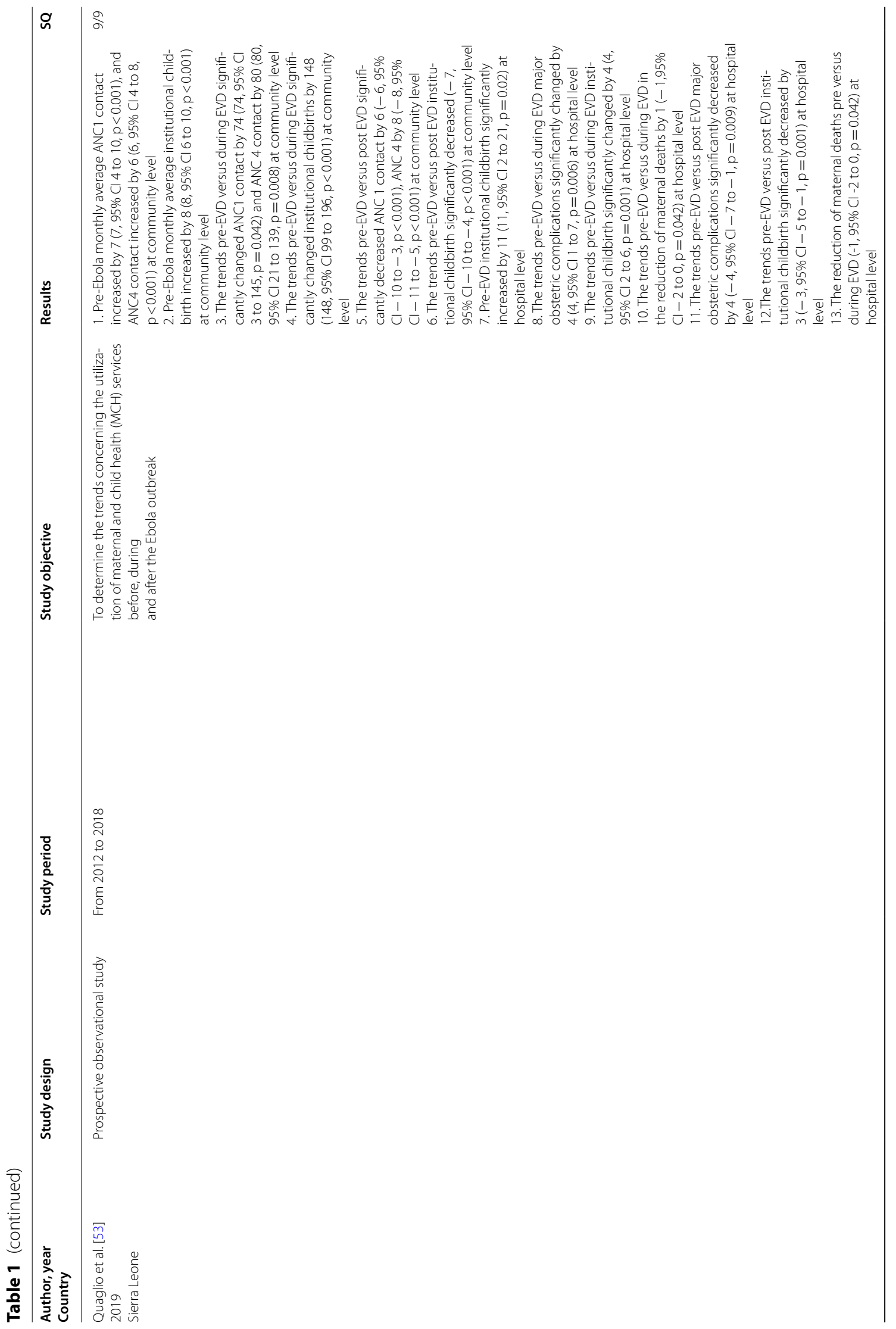




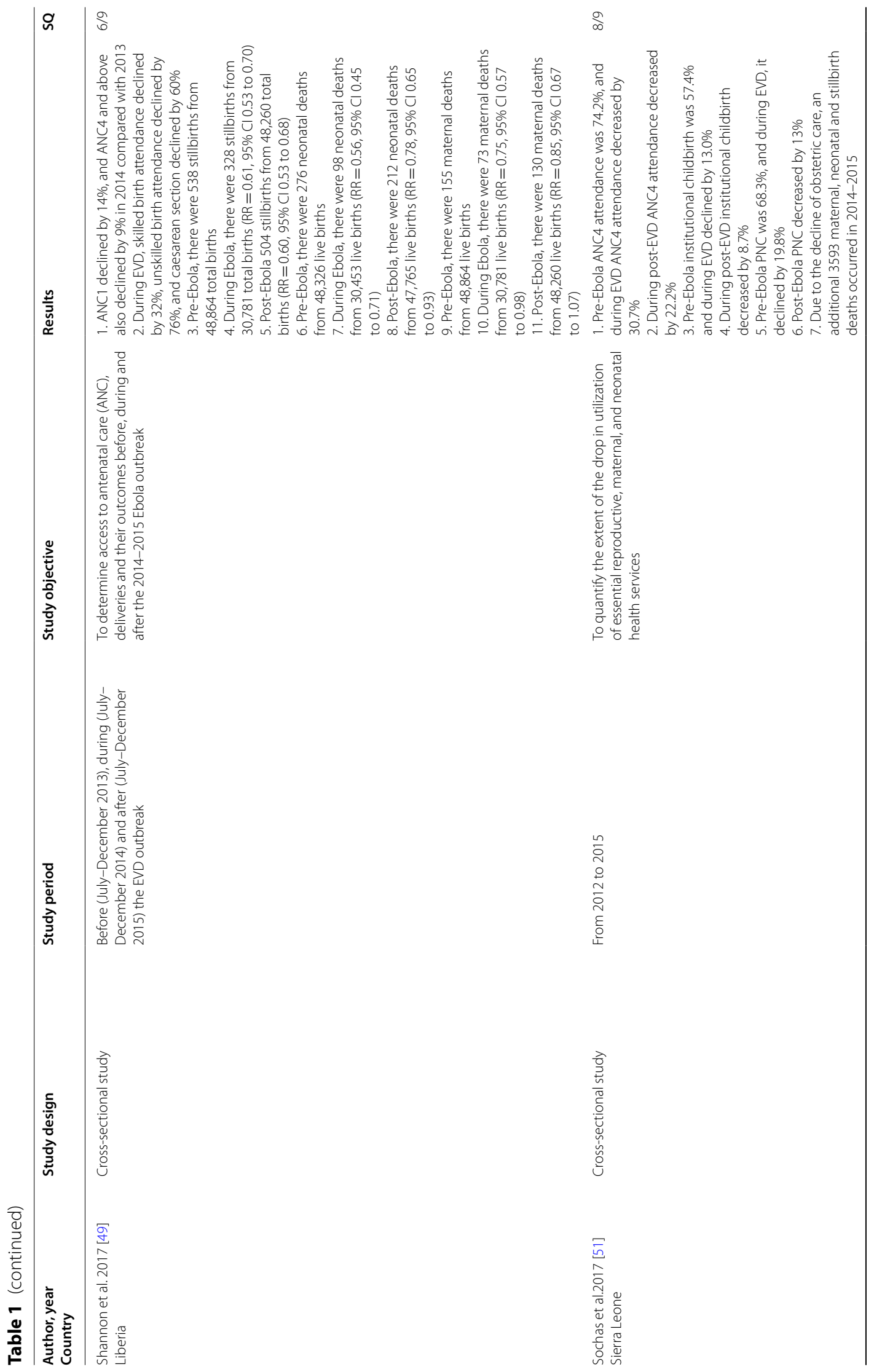




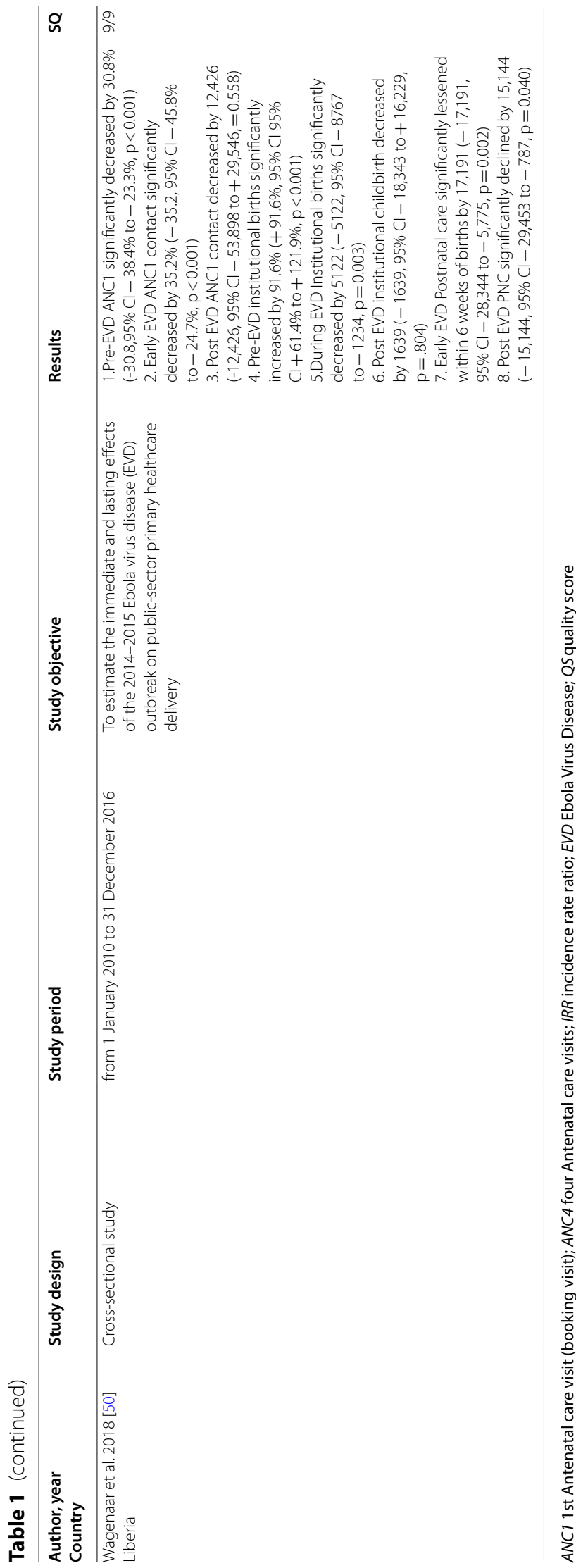


Table 2 Characteristics of included studies for systematic review

\begin{tabular}{llll}
\hline Category & Subcategory & Frequency & Percent (\%) \\
\hline Study design & Cross sectional & 8 & 66.7 \\
& Ecological & 1 & 8.3 \\
& Case series & 1 & 8.3 \\
& Retrospective cohort & 1 & 8.3 \\
& Prospective cohort & 1 & 8.3 \\
Year of publication & 2015 & 1 & 8.3 \\
& 2016 & 3 & 25 \\
& 2017 & 5 & 41.7 \\
& 2018 & 2 & 16.7 \\
& 2019 & 1 & 8.3 \\
\hline
\end{tabular}

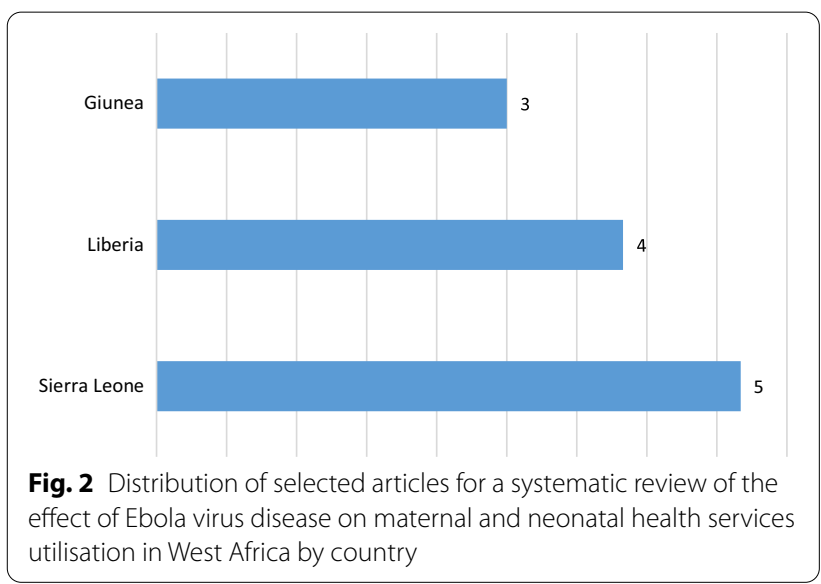

all included articles were published within 2015-2019 (Table 2). In addition, the included articles were from 3 West African countries (Guinea, Liberia, and Sierra Leone), $41.7 \%$ of the studies were from Sierra Leone [17, $35,51-53], 33.3 \%$ were from Liberia $[18,39,49,50]$ and $25 \%$ were from Guinea $[16,47,48]$ (Fig. 2).

\section{Antenatal care}

Nine studies showed the effect of EVD on antenatal attendance [16, 17, 47-53] (Table 1). ANC attendance in Guinea, Sierra Leone and Liberia significantly decreased during the EVD outbreak. For example, a study conducted at Macenta district Guinea [47] showed that pre-EVD on average 2053 pregnant women attended per month for their first ANC, while pregnant women attendance for their first ANC declined on average per month by $59 \%$ (842) and similar trends have happened in ANC 3 and above during EVD outbreak. Post-EVD attending ANC1 increased 1260 per month and recovered by $63 \%$. The recovery gap was $(37 \%, \mathrm{p}<0.001)$ compared with pre-EVD attending ANC1 (Table1).
In addition, a study conducted at Forest region Guinea [16] revealed that pre-EVD on average attending ANC1 substantially increased per month by 109 (109, 95\% CI 54 to $164, \mathrm{p}=0.0005)$, and attending ANC3 and above also significantly increased by $119(119,95 \%$ CI 79 to 158 , $\mathrm{p}<0.0001)$. However, attending ANC1 on average significantly decreased per month by $418(-418,95 \%$ CI -535 to $-300, \mathrm{p}<0.0001$ ), and attending ANC3 and above also significantly decreased by $363(-363,95 \%$ CI -485 to $-242, p<0.0001)$ during the EVD outbreak. The overall trend during versus post-EVD attending ANC1 on average significantly declined per month by $136(-136,95 \%$ $\mathrm{CI}-231$ to $-40 ; \mathrm{p}=0.0075)$, but the post-EVD attending ANC3 and above were not significantly different (13, $95 \% \mathrm{CI}-109$ to $134, \mathrm{p}=0.8286$ ) (Table 1 ).

A similar study conducted in Guinea [48] revealed that, on average, 1617 women attended ANC at least once (ANC1) in $2013(1617 \pm 53)$, but on average, 1065 women attended ANC1 and above during the EVD outbreak in $2014(1065 \pm 29, \mathrm{p}=0.0004)$ in EVD affected areas. It indicated that attending ANC1 and above significantly declined in Guinea Ebola-affected areas during the EVD outbreak. On average, 1817 women attended ANC1 and above in 2013 (1817 \pm 331 ), but on average, 1689 women attended ANC1 and above during the EVD outbreak in 2014 $(1689 \pm 280, \mathrm{p}=0.5696)$ in EVD unaffected areas. The study also showed that attendance at ANC1 and above did not significantly change in areas that were not affected by Ebola in Guinea (Table 1).

A study conducted in Liberia [50] showed that preEVD (January 2010-May 2014), attending ANC1 significantly decreased by $30.8 \%$ (95\% CI $-38.4 \%,-23.3 \%$, $\mathrm{p}<0.001$ ). During EVD, attending ANC1 also significantly decreased by $35.2 \%$ (95\% CI $-45.8 \%$ to $-24.7 \%$, $\mathrm{p}<0.001)$. Similarly, attending ANC1 and above significantly decreased by $18 \%($ IRR $=0.82,95 \%$ CI 0.79 to 0.84$)$ in Sierra Leone [17] (Table 1). A study conducted at Pujehun district in Sierra Leone [53] showed that pre-EVD, attending ANC1 were on average seven times more likely to increase per month $(7,95 \%$ CI 4 to $10, \mathrm{p}<0.001)$, and attending $\mathrm{ANC} 4$ were six times more likely to increase per month $(6,95 \% \mathrm{CI} 4$ to $8, \mathrm{p}<0.001)$ at the community level. Whereas the trend pre-EVD versus post-EVD attending ANC1 were six times more likely to decrease per month $(-6,95 \% \mathrm{CI}-10$ to $-3, \mathrm{p}<0.001)$, and attending ANC4 were eight times more likely to decrease $(-8,95 \% \mathrm{CI}-11$ to $-5, \mathrm{p}<0.001)$ at the community level (Table 1).

\section{Institutional and mode of childbirth}

Eleven studies reported the effect of EVD on institutional childbirth [16-18, 35, 39, 47, 49-53] (Table 1). Institutional childbirth in Guinea, Sierra Leone and 
Liberia significantly decreased during the EVD outbreak compared with the same season pre-EVD. A nationwide study conducted in Sierra Leone [35] revealed that pre-EVD, the number of women attending institutional childbirth was 394. In contrast, institutional childbirth decreased by $28 \%$ (283) during EVD.

A study conducted in Sierra Leone [17] showed that institutional childbirth significantly decreased, by $11 \%$ (IRR $=0.89,95 \%$ CI 0.87 to $0.91, \mathrm{p}<0.001)$ during the EVD outbreak. A study conducted at Pujehun district in Sierra Leone [53] showed that pre-EVD, women were on average eight times more likely to attend institutional childbirth per month $(8,95 \%$ CI 6 to 10 , $\mathrm{p}<0.001)$ at the community level. Post-EVD women were seven times less likely to attend institutional childbirth $(-7,95 \% \mathrm{CI}-10$ to $-4, \mathrm{p}<0.001)$ at the community level. Similarly, pre-EVD women were on average eleven times more likely to attend institutional childbirth per month $(11,95 \%$ CI 2 to $21, \mathrm{p}=0.02)$ at the hospital level. Post-EVD, women were four times more likely to attend institutional childbirth (4, 95\% CI 2 to $6, p=0.001$ ) at the hospital level (Table 1 ).

A study conducted in Forest region Guinea [16] revealed that pre-EVD, institutional childbirth on average had significantly increased by 61 per month $(61,95 \%$ CI 38 to $84, \mathrm{p}<0.0001)$. Institutional childbirth on average significantly decreased by 240 per month $(-240,95 \%$ CI -293 to $-187 ; \mathrm{p}<0.0001$ ) during the EVD outbreak. The overall trend in institutional childbirth during EVD versus post EVD was not significantly different $(-30,95 \%$ CI -80 , to $20, p=0 \cdot 2294$ ) (Table 1 ).

A study conducted in Rivercess County, Liberia [18] showed that institutional childbirth significantly decreased by $30 \%$ during EVD ( $\mathrm{AOR}=0.70,95 \% \mathrm{CI}$ $0.50-0.98, \mathrm{p}=0.037)$. A nationwide study conducted in Liberia [49] revealed that pre-EVD 6468 births were attended by skilled health care providers, but only 4367 births were attended by skilled health care providers during EVD. These figures demonstrate that institutional childbirth decreased by $32 \%$ during EVD (Table 1 ).

Three studies reported the effect of EVD on caesarean section birth rates [35, 47, 49] (Table 1). Caesarean section childbirth in Guinea, Sierra Leone and Liberia significantly declined during the EVD outbreak. A nationwide study conducted in Sierra Leone [35] showed that pre-EVD caesarean section birth was 112 per week and that caesarean section birth rates decreased by $20 \%$ (89) during EVD. In Guinea [47] caesarean section birth rates significantly decreased during EVD. In contrast, full recovery has been noted in the post-Ebola monthly mean of caesarean section $(37, \mathrm{SD}=8)$ compared to the pre-Ebola level (38, $\mathrm{SD}=7, \mathrm{p}=0.692$ ). A nationwide study conducted in Liberia [49] revealed that pre-EVD
472 women gave birth by caesarean section while 191 women gave birth by caesarean section during EVD, indicating that caesarean section birth rates declined by $32 \%$ (Table 1).

Importantly, five studies reported the effect of EVD on maternal and neonatal mortality [17, 47, 49, 51, 53] (Table 1). Maternal and neonatal mortality rates in Guinea, Sierra Leone, and Liberia decreased during the EVD outbreak. A study conducted in Sierra Leone [17] showed that the maternal mortality ratio at the health facilities significantly increased by $34 \%$ (IRR $=1.34$, $95 \%$ CI 1.07 to $1.69, \mathrm{p}=0.01$ ) during the EVD outbreak, and the stillbirth rate significantly increased by $24 \%(\mathrm{IRR}=1.24,95 \%$ CI 1.14 to $1.35, \mathrm{p}<0.001)$ during the EVD outbreak. Notably, a study conducted in Sierra Leone [53] revealed that pre-EVD maternal deaths significantly decreased by $1(-1,95 \% \mathrm{CI}-2$ to $0, \mathrm{p}=0.042)$ at the hospital level compared with EVD outbreak. Another study conducted in Sierra Leone [51] showed that an additional 3593 maternal deaths, neonatal deaths, and stillbirth occurred in 2014-2015 (Table 1).

Furthermore, a study conducted in Guinea [47] showed maternal deaths were low and remained similar across pre, during and post EVD (0.1-0.2\%, p >0.05). Similarly, stillbirths were low and remained similar across pre, during and post-EVD. Neonatal deaths were also low pre and during (range 1.1-1.7\%) but were higher in the postEbola period compared to the pre-Ebola period $(\mathrm{p}<0.01)$.

A study conducted in Liberia [49] revealed that maternal deaths decreased by $25 \%$ during EVD $((\mathrm{RR}=0.75$, 95\% CI 0.57 to 0.98). Whereas post EVD maternal deaths increased by $15 \% \quad(\mathrm{RR}=0.85,95 \% \mathrm{CI} 0.67$ to 1.07$)$ and similar with pre EVD. Stillbirth increased by $39 \%$ during EVD ( $R R=0.61,95 \%$ CI 0.53 to 0.70$)$. Similarly, stillbirth increased by $40 \%$ post $E V D(R R=0.60,95 \%$ CI 0.53 to 0.68 ). Neonatal deaths decreased by $44 \%$ during EVD $(\mathrm{RR}=0.56,95 \% \mathrm{CI} 0.45$ to 0.71$)$, but neonatal deaths decreased by $22 \%$ post EVD ( $R R=0.78,95 \%$ CI 0.65 to $0.93)$ compared with pre-EVD. This number showed that neonatal deaths were lower during EVD than pre EVD and post EVD (Table 1).

\section{Postnatal care}

Four studies reported the effect of EVD on institutional childbirth [17, 50-52] (Table 1). PNC in Sierra Leone and Liberia decreased during the EVD outbreak. A study conducted in Liberia [50] showed that during EVD, postnatal care significantly decreased within six weeks of births by $17,191(-17,191,95 \% \mathrm{CI}-28344$ to $-5775, \mathrm{p}=0.002)$ and noticeably PNC significantly decreased post-EVD by $15,144(-15,144,95 \% \mathrm{CI}-29,453,-787, \mathrm{p}=0.040)$. A study conducted in Sierra Leone [17] also revealed that attending PNC decreased by $22 \%$ during EVD 
$(\mathrm{IRR}=0.78,95 \%$ CI 0.75 to 0.80$)$. In Sierra Leone [51], a study showed that pre-EVD PNC utilisation was $68.3 \%$. Whereas PNC decreased by $19.8 \%$ during the outbreak and recovered $13 \%$ post-EVD (Table 1 ).

\section{Discussion}

The purpose of this systematic review was to identify, appraise and synthesise studies that reported the effect of EVD on maternal health service utilisation in West Africa. This systematic review showed that antenatal care, institutional childbirth, and postnatal care significantly decreased during EVD in three countries (Guinea, Liberia, and Sierra Leone). This review included three articles from Guinea, four articles from Liberia, and five articles from Sierra Leone. Institutional childbirth was reported in eleven studies, caesarean section and postnatal care were each reported in three studies. Within countries, institutional childbirth was reported in five studies in Sierra Leone, ANC was reported in four studies in Sierra Leone, PNC was reported in three studies in Sierra Leone, and PNC wasn't reported in Guinea. Importantly, this systematic review presented maternal health services utilisation and perinatal outcomes preEVD, during EVD and post-EVD.

Among the findings, studies conducted in Guinea [16] and Sierra Leone [53] showed that pre-EVD, women were more likely to attend ANC1 and above. This finding is consistent with studies performed in Liberia [54], Sierra Leone [55], and Guinea [56]. Obstetric care providers, governments, maternal and child health advocates of these countries implemented effective interventions pre-EVD, for example, providing free health services [22] to improve ANC utilisation to reduce maternal and neonatal mortality [57].

The current review showed that in Guinea $[16,47]$ and Liberia $[49,50]$ showed significantly decreased in attending ANC1 and above during EVD, while one study in Sierra Leone [52] showed that attending ANC1 and above had no significant difference pre and during Ebola outbreak. This study was conducted in a rural district that experienced low Ebola cases than other areas. This finding is consistent with a study conducted in Taiwan [58] on SARS-1 and a review in West Africa [31], and a systematic review on Ebola [59]. The reduction of attending ANC 1 and above could be due to the absence of health care providers, a shortage of personal protective equipment, women beliefs that hospitals are exposure centres, the shutdown of some health institutions, the health care providers contracting Ebola virus and death [60], and/or distrust between health care providers and the community [61].
Notwithstanding, there was no significant change during EVD in the unaffected areas in Guinea [48]. Studies in Guinea [16, 47] and Sierra Leone [53] showed that ANC utilisation also significantly increased post-EVD but did not reach pre-EVD level. These findings suggest that EVD disturbed ANC services. To curb these problems, the international community, responsible bodies, and health care providers need to implement extraordinary interventions tailored to the local community to achieve Sustainable Development Goal 3 by 2030.

Institutional childbirth before EVD significantly increased in Guinea [16], Liberia [50], and Sierra Leone [53], while other studies in Guinea [47] and Liberia [18, 39] showed that institutional childbirth increased to some extent before EVD. These findings are similar to those of studies performed in Liberia [54], Sierra Leone [55], and Guinea [56]. In addition, studies conducted in Guinea [16], Liberia [18, 50], and Sierra Leone [17, 53] showed that women were less likely to have an institutional birth during EVD. These findings coincide with a study conducted in Taiwan [58], a study conducted in West Africa $[14,31]$ and a systematic review of the effect of Ebola on pregnancy and breast-feeding mothers [59]. These interruptions could be lack of transport due to lockdown, loss of income, lower health-seeking behaviour due to EVD, community mistrusted the health care providers and the health system [62] and shut down some health facilities [35].

Importantly, post-EVD women were more likely to have an institutional birth, indicating a recovery in Guinea [16, 47], Liberia [50] and Sierra Leone [53]. One study found the rate had returned to the pre-EVD period [16], while the others $[47,50,53]$ had not fully recovered to the pre-EVD level of utilisation of institutional childbirth. The institutional childbirths could have recovered due to the resilience of the maternal health system, which is based on trust built between the community and health care providers, the capability of the healthcare facilities and deploying additional obstetric care providers in the highly EVD affected areas.

Caesarean section birth rates in Guinea [47], Sierra Leone [35] and Liberia [49] significantly declined during the EVD outbreak. In a nationwide study conducted in Sierra Leone, caesarean section decreased by $20 \%$ during EVD. Similarly, a nationwide study in Liberia showed that caesarean section decreased by $32 \%$ during EVD. Besides, a study conducted in Guinea showed that caesarean section births significantly decreased during EVD. In contrast, full recovery has been noted in the postEbola monthly mean of caesarean section $(37, \mathrm{SD}=8)$ compared to the pre-Ebola level $(38, \mathrm{SD}=7, \mathrm{p}=0.692)$. 
This finding is consistent with a study conducted in West Africa [14].

The current systematic review also showed that during EVD, there were higher rates of maternal mortality in Sierra Leone [17, 51], but during EVD, maternal mortality rates were lower than before EVD in Guinea [47] and Liberia [49]. Similarly, stillbirth and neonatal deaths were less likely to occur during EVD [49]. This decrease might be due to the shutdown of some health facilities, underreporting or reporting errors, and increasing numbers of home birth. Moreover, this systematic review showed that during EVD, PNC also significantly decreased in studies performed in Liberia [50] and Sierra Leone [17]. Decrease in PNC might be due to fear of acquiring EVD by postpartum mothers, their family and health care providers' and a resulting pressure to discharge early. Contributing factors included economic recession, lack of transportation [62] and shutdown of health facilities [35] due to EVD.

This review has synthesised the current evidence of the effect of EVD on maternal health service utilisation and perinatal outcomes during EVD and post-EVD. Strengths of the study include that it systematically synthesised evidence on the effect of EVD on ANC, institutional childbirth, PNC, and perinatal outcomes. Data extraction and evidence synthesis were done by three reviewers, to strengthen the reliability of the study outcomes and minimise the subjectivity of evidence synthesis and interpretation. The quality of included studies was appraised using the Joanna Brigg's Institute (JBI) validated quality appraisal method [44]. All studies included in this paper indexed in Medline, PubMed, CINAHL, Scopus, EMBASE and African journals online databases and published in English. Besides these strengths, the limitation of the systematic review a study focused on the access of ANC, institutional childbirth, PNC, and perinatal outcomes rather than on the quality of ANC, institutional childbirth, and PNC. Quality of ANC, institutional childbirth, and PNC are useful to consider, as access to poor quality services could increase maternal and perinatal morbidity and mortality. Data collection carried out after the outbreak ended is subject to social desirability and recall bias. Other limitations are lack of coverage of ANC, institutional childbirth, and PNC due to having no population-level denominators. Most of the data has been taken from records; there are under or overestimated data.

\section{Conclusion}

Based on our findings, rates of antenatal care, institutional childbirth, and postnatal care were attempting to recover post-Ebola virus disease. We have three recommendations based on the synthesis of this review. Firstly, responsible bodies and stakeholders need to prepare locally tailored interventions to increase the number of women attending ANC, institutional childbirth, and PNC services post-EVD and future outbreaks including COVID-19. Secondly, in order to build trust, creating community networks between health care providers and trusted community leaders may increase the number of women attending ANC, institutional childbirth, and PNC services post-EVD and during future outbreaks. Thirdly, governments and stakeholders need to establish a non-epidemic task force that provides equipment and monitors maternal health services to sustain services post- EVD and during future outbreaks. Further rigorous studies are needed to examine health centre and hospital availability, accessibility, and capacity to deliver maternal health services.

\section{Abbreviations}

ANC: Antenatal care; EVD: Ebola virus disease; PNC: Postnatal care; WHO: World Health Organization.

\section{Acknowledgements}

The author would like to acknowledge UTS librarian Sarah Su for her help with the search strategy and Akalu Yeshambel and Catherine Mc Corkill for their help with English grammar. The authors also extend their heartfelt thanks to the authors of primary papers included in this review.

\section{Authors' contributions}

ZYK developed the draft proposal under the supervision of DF and VS. All authors (ZYK, VS and DF) made a significant contribution to the conception and conceptualisation of the study protocol. All authors read and approved the final manuscript.

\section{Funding}

There was no funding or sponsoring organisation for this paper.

Availability of data and materials

Most of the data analysed during the systematic review are included in this manuscript.

\section{Declarations}

Ethics approval and consent to participate

Not applicable.

\section{Consent for publication}

Not applicable.

\section{Competing interest}

The authors declare that there are no competing interests.

\section{Author details}

${ }^{1}$ Department of Midwifery, College of Medicine and Health Sciences, Hawassa University, Hawassa, Ethiopia. ${ }^{2}$ Centre for Midwifery, Child and Family Health, Faculty of Health, University of Technology Sydney, Sydney, Australia.

Received: 17 September 2020 Accepted: 13 January 2022

Published online: 04 February 2022

\section{References \\ 1. Iliyasu G, Dattijo LM, Habib AG. Ebola virus disease and pregnancy out- come: a review of the literature. Trop J Obstet Gynaecol. 2017;34(1):6-10.}


2. Bell BP, Damon IK, Jernigan DB, Kenyon TA, Nichol ST, O'Connor JP, et al. Overview, control strategies, and lessons learned in the CDC response to the 2014-2016 Ebola epidemic. MMWR Suppl. 2016;65(3):4-11.

3. Kuhn JH, Bao Y, Bavari S, Becker S, Bradfute S, Brister JR, et al. Virus nomenclature below the species level: a standardised nomenclature for laboratory animal-adapted strains and variants of viruses assigned to the family Filoviridae. Adv Virol. 2013;158(6):1425-32.

4. Kuhn JH, Amarasinghe GK, Basler CF, Bavari S, Bukreyev A, Chandran K, et al. ICTV virus taxonomy profile: Filoviridae. J Gen Virol. 2019;100(6):911-2.

5. Feldmann H, Geisbert TW. Ebola haemorrhagic fever. Lancet. 2011;377(9768):849-62.

6. Towner JS, Amman BR, Sealy TK, Carroll SAR, Comer JA, Kemp A, et al. Isolation of genetically diverse Marburg viruses from Egyptian fruit bats. PLoS Pathog. 2009;5(7):e1000536.

7. Bundu I, Patel A, Mansaray A, Kamara T, Hunt L. Surgery in the time of Ebola: how events impacted on a single surgical institution in Sierra Leone. BMJ Military Health. 2016;162(3):212-6.

8. Jacob ST, Crozier I, Fischer WA, Hewlett A, Kraft CS, de La Vega M-A, et al. Ebola virus disease. Nat Rev Dis Primers. 2020;6(1):1-31.

9. Caluwaerts S, Fautsch T, Lagrou D, Moreau M, Modet Camara A, Günther $S$, et al. Dilemmas in managing pregnant women with Ebola: 2 case reports. Clin Infect Dis. 2016;62(7):903-5.

10. Burke J, Declerq R, Ghysebrechts G, Pattyn S, Piot P, Ronsmans M, et al. Ebola haemorrhagic-fever in Zaire, 1976-report of an International-Commission. Bull World Health Organ. 1978;56(2):271-93.

11. Kaner J, Schaack S. Understanding Ebola: the 2014 epidemic. Glob Health. 2016;12(1):1-7.

12. World Health Organisation WHO. Statement on the 1st meeting of the IHR Emergency Committee on the 2014 Ebola outbreak in West Africa. WHO website. August 8. 2015

13. World Health Organization. Situation report: Ebola virus disease, 10 June 2016. Geneva: World Health Organization; 2016.

14. Wilhelm JA, Helleringer S. Utilization of non-Ebola health care services during Ebola outbreaks: a systematic review and meta-analysis. J Glob Health. 2019;9:1.

15. World Health Organisation WHO. Trends in maternal mortality 2000 to 2017: estimates by WHO, UNICEF, UNFPA, World Bank Group and the United Nations Population Division. 2019.

16. Delamou A, El Ayadi AM, Sidibe S, Delvaux T, Camara BS, Sandouno SD, et al. Effect of Ebola virus disease on maternal and child health services in Guinea: a retrospective observational cohort study. Lancet Glob Health. 2017;5(4):e448-57.

17. Jones SA, Gopalakrishnan S, Ameh CA, White S, van den Broek NR "Women and babies are dying but not of Ebola": the effect of the Ebola virus epidemic on the availability, uptake and outcomes of maternal and new-born health services in Sierra Leone. BMJ Glob Health. 2016;1(3):e000065.

18. Ly J, Sathananthan V, Griffiths T, Kanjee Z, Kenny A, Gordon N, et al. Facility-based delivery during the Ebola virus disease epidemic in rural Liberia: analysis from a cross-sectional, population-based household survey. PLoS Med. 2016;13(8):e1002096.

19. Campbell OM, Graham WJ. Strategies for reducing maternal mortality: getting on with what works. Lancet. 2006;368(9543):1284-99.

20. Bekele BB, Dadi TL, Tesfaye T. The significant association between maternity waiting homes utilisation and perinatal mortality in Africa: systematic review and meta-analysis. BMC Res Notes. 2019;12(1):1-6.

21. Lori JR, Munro ML, Rominski S, Williams G, Dahn BT, Boyd CJ, et al. Maternity waiting homes and traditional midwives in rural Liberia. Int J Gynaecol Obstet. 2013;123(2):114-8.

22. Donnelly J. How did Sierra Leone provide free health care? Lancet. 2011;377(9775):1393-6.

23. Van Lerberghe W, Matthews Z, Achadi E, Ancona C, Campbell J, Channon $A$, et al. Country experience with a strengthening of health systems and deployment of midwives in countries with high maternal mortality. Lancet. 2014;384(9949):1215-25.

24. Brazier E, Fiorentino R, Barry MS, Diallo M. The value of building health promotion capacities within communities: evidence from a maternal health intervention in Guinea. Health Policy Plan. 2015;30(7):885-94.

25. World Health Organization. Trends in maternal mortality: 1990 to 2013 : estimates by WHO, UNICEF, UNFPA, The World Bank and the United
Nations Population Division: executive summary. World Health Organization; 2014.

26. Akombi BJ, Renzaho AM. Perinatal mortality in sub-Saharan Africa: a meta-analysis of demographic and health surveys. Ann Glob Health. 2019;85:1.

27. Piot P, Muyembe J-J, Edmunds WJ. Ebola in west Africa: from disease outbreak to humanitarian crisis. Lancet Infect Dis. 2014;14(11):1034-5.

28. Brolin Ribacke KJ, Saulnier DD, Eriksson A, Von Schreeb J. Effects of the West Africa Ebola virus disease on healthcare utilisation-a systematic review. Front Public Health. 2016;4:222.

29. Bebell LM, Oduyebo T, Riley LE. Ebola virus disease and pregnancy: a review of the current knowledge of Ebola virus pathogenesis, maternal, and neonatal outcomes. Birth defects research. 2017;109(5):353-62.

30. UNFPA. Ebola wiping out gains in safe motherhood. 2014.

31. Delamou A, Hammonds RM, Caluwaerts S, Utz B, Delvaux T. Ebola in Africa: beyond epidemics, reproductive health in crisis. Lancet. 2014;384(2105):62364-73.

32. Kieny MP, Evans DB, Schmets G, Kadandale S. Health-system resilience: reflections on the Ebola crisis in western Africa. Bull World Health Organ. 2014;92(12):850.

33. Bolkan HA, Bash-Taqi DA, Samai M, Gerdin M, von Schreeb J. Ebola, and indirect effects on health service function in Sierra Leone. PLoS Currents. 2014;6:19.

34. Elston J, Cartwright C, Ndumbi P, Wright J. The health impact of the 2014-15 Ebola outbreak. Public Health. 2017;143:60-70.

35. Brolin Ribacke KJ, van Duinen AJ, Nordenstedt H, Höijer J, Molnes R, Froseth TW, et al. The impact of the West Africa Ebola outbreak on obstetric health care in Sierra Leone. PLoS ONE. 2016;11(2):e0150080.

36. Gizelis T-I, Karim S, Østby G, Urdal H. Maternal health care in the time of Ebola: a mixed-method exploration of the impact of the epidemic on delivery services in Monrovia. World Dev. 2017;98:169-78.

37. Ellington S, Perez M, Morof D, Zotti ME, Callaghan W, Meaney-Delman $D$, et al. Addressing maternal health during CDC's Ebola response in the United States. J Womens Health. 2017;26(11):1141-5.

38. Baggi F, Taybi A, Kurth A, Van Herp M, Di Caro A, Wölfel R, et al. Management of pregnant women infected with Ebola virus in a treatment centre in Guinea, June 2014. Euro Surveill. 2014;19(49):20983.

39. Lori JR, Rominski SD, Perosky JE, Munro ML, Williams G, Bell SA, et al. A case series study on the effect of Ebola on facility-based deliveries in rural Liberia. BMC Pregn Childbirth. 2015;15(1):1-6.

40. Black BO, Caluwaerts S, Achar J. Ebola viral disease and pregnancy. Obstet Med. 2015:8(3):108-13.

41. Theuring S, Koroma AP, Harms G. "In the hospital, there will be nobody to pamper me": a qualitative assessment on barriers to facility-based delivery in post-Ebola Sierra Leone. Reprod Health. 2018;15(1):1-9.

42. Yerger $P$, Jalloh $M$, Coltart CEM, King C. Barriers to maternal health services during the Ebola outbreak in three West African countries: a literature review. BMJ Glob Health. 2020;5(9):e002974.

43. Liberati A, Altman DG, Tetzlaff J, Mulrow C, Gøtzsche PC, loannidis JP, et al. The PRISMA statement for reporting systematic reviews and meta-analyses of studies that evaluate health care interventions: explanation and elaboration. J Clin Epidemiol. 2009;62(10):e1-34.

44. Institute J. The Joanna Briggs Institute Critical Appraisal Tools for Use in JBI Systematic Reviews Checklist for Analytical Cross-Sectional Studies. The Joanna Briggs Institute North Adelaide, Australia; 2017

45. Popay J, Roberts H, Sowden A, Petticrew M, Arai L, Rodgers M, et al. Guidance on the conduct of narrative synthesis in systematic reviews. A product from the ESRC methods programme Version. 2006;1:92.

46. Kerber KJ, de Graft-Johnson JE, Bhutta ZA, Okong P, Starrs A, Lawn JE. Continuum of care for maternal, new-born, and child health: from slogan to service delivery. Lancet. 2007;370(9595):1358-69.

47. Camara BS, Delamou A, Diro E, Béavogui AH, El Ayadi AM, Sidibé S, et al. Effect of the 2014/2015 Ebola outbreak on reproductive health services in a rural district of Guinea: an ecological study. Trans R Soc Trop Med Hyg. 2017;111(1):22-9.

48. Leno NN, Delamou A, Koita Y, Diallo TS, Kaba A, Delvaux T, et al. Ebola virus disease outbreak in Guinea: what effects on prevention of motherto-child transmission of HIV services? Reprod Health. 2018;15(1):60.

49. Shannon F, Horace-Kwemi E, Najjemba R, Owiti P, Edwards J, Shringarpure K, et al. Effects of the 2014 Ebola outbreak on antenatal care and 
delivery outcomes in Liberia: a nationwide analysis. Public Health Action. 2017;7(1):S88-93.

50. Wagenaar BH, Augusto O, Beste J, Toomay SJ, Wickett E, Dunbar N, et al. The 2014-2015 Ebola virus disease outbreak and primary healthcare delivery in Liberia: Time-series analyses for 2010-2016. PLoS Med. 2018;15(2):e1002508.

51. Sochas L, Channon AA, Nam S. Counting indirect crisis-related deaths in the context of a low-resilience health system: the case of maternal and neonatal health during the Ebola epidemic in Sierra Leone. Health Policy Plan. 2017;32(suppl_3):iii32-9.

52. Caulker V, Mishra S, Van Griensven J, Moosa A, Najjemba R, Shringarpure $K$, et al. Life goes on: the resilience of maternal primary care during the Ebola outbreak in rural Sierra Leone. Public Health Action. 2017;7(1):S40-6.

53. Quaglio G, Tognon F, Finos L, Bome D, Sesay S, Kebbie A, et al. Impact of Ebola outbreak on reproductive health services in a rural district of Sierra Leone: a prospective observational study. BMJ Open. 2019;9(9):e029093.

54. Yaya S, Uthman OA, Bishwajit G, Ekholuenetale M. Maternal health care service utilisation in post-war Liberia: analysis of nationally representative cross-sectional household surveys. BMC Public Health. 2019:19(1):28.

55. Jalloh MB, Bah AJ, James PB, Sevalie S, Hann K, Shmueli A. Impact of the free healthcare initiative on wealth-related inequity in the utilisation of maternal \& child health services in Sierra Leone. BMC Health Serv Res. 2019;19(1):352.

56. Greenwell KF, Winner M. Infant survival outcomes in Guinea in light of improved maternal and childcare: Further analysis of the 2005 and 2012 demographic and health surveys: ICF International; 2014.

57. Streifel C. How did Ebola impact maternal and child health in Liberia and Sierra Leone. A report of the CSIS Global Health Policy Center Washington DC, USA: Center for Strategic \& International Studies. 2015.

58. Lu T-H, Chou Y-J, Liou C-S. Impact of SARS on healthcare utilisation by disease categories: implications for delivery of healthcare services. Health Policy. 2007;83(2-3):375-81.

59. Foeller ME, Carvalho Ribeiro do Valle C, Foeller TM, Oladapo OT, Roos E, Thorson AE. Pregnancy and breastfeeding in the context of Ebola: a systematic review. Lancet Infect Dis. 2020;20(7):e149-58.

60. Olu O, Kargbo B, Kamara S, Wurie AH, Amone J, Ganda L, et al. Epidemiology of Ebola virus disease transmission among health care workers in Sierra Leone, May to December 2014: a retrospective descriptive study. BMC Infect Dis. 2015;15(1):1-9.

61. Cheung E. An outbreak of fear, rumours, and stigma: psychosocial support for the Ebola Virus Disease outbreak in West Africa. Intervention. 2015;13(1):70-6.

62. Massaquoi H, Atuhaire C, Chinkonono GS, Christensen BN, Bradby H, Cumber SN. Exploring health-seeking behavior among adolescent mothers during the Ebola epidemic in Western rural district of Freetown, Sierra Leone. BMC Pregn Childbirth. 2021;21(1):37.

\section{Publisher's Note}

Springer Nature remains neutral with regard to jurisdictional claims in published maps and institutional affiliations.

Ready to submit your research? Choose BMC and benefit from:

- fast, convenient online submission

- thorough peer review by experienced researchers in your field

- rapid publication on acceptance

- support for research data, including large and complex data types

- gold Open Access which fosters wider collaboration and increased citations

- maximum visibility for your research: over $100 \mathrm{M}$ website views per year

At BMC, research is always in progress.

Learn more biomedcentral.com/submissions 